\title{
Collaborative Design: Supporting Lasting Social Change
}

\section{ANN YOACHIM, Director \& Professor or Practice}

Albert and Tina Small Center for Collaborative Design

NICK JENISCH, Project Manager

Albert and Tina Small Center for Collaborative Design

\section{EMILIE TAYLOR, AIA, Design/Build Manager, Favrot II Professor of Practice}

Tulane University \&

Albert and Tina Small Center for Collaborative Design

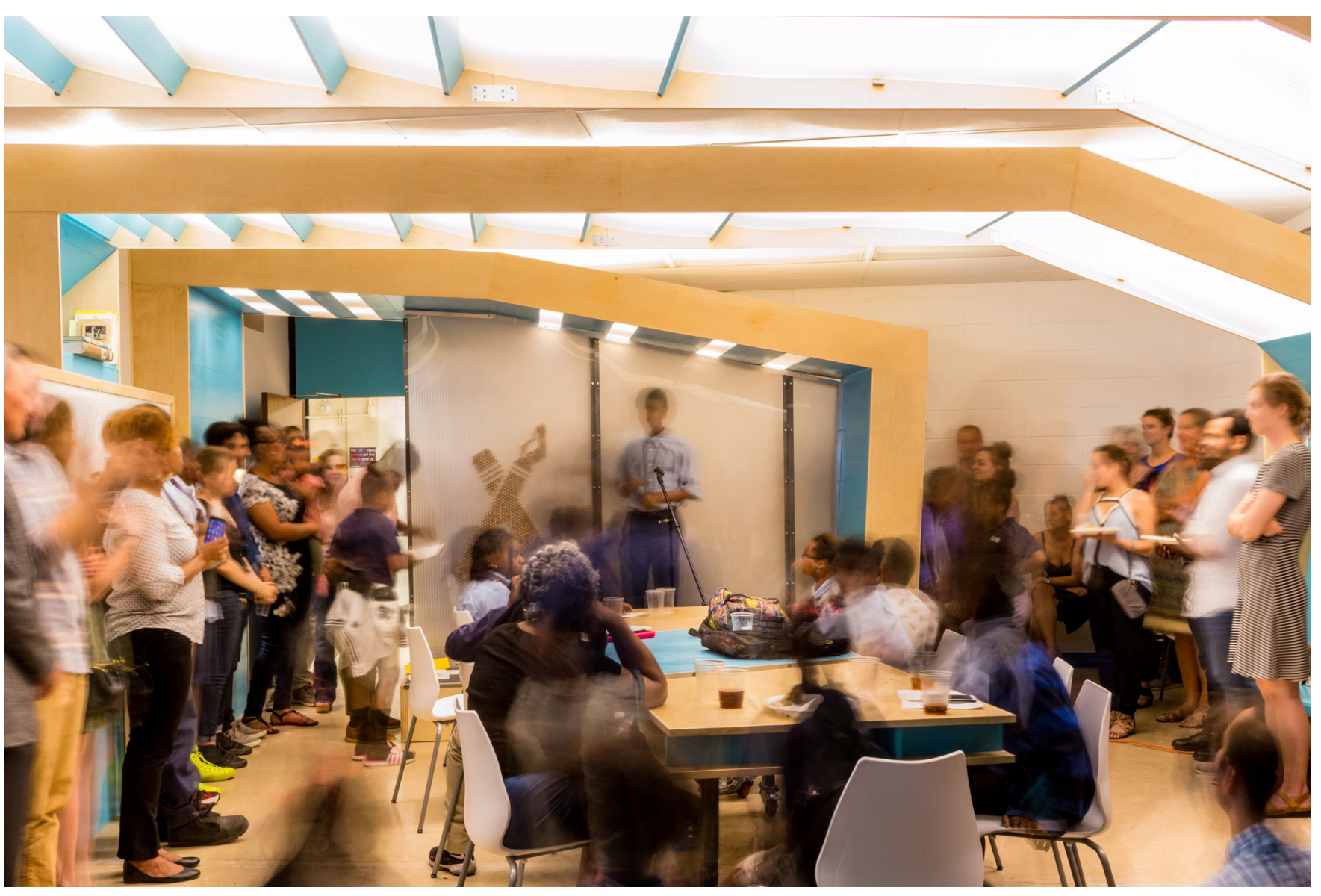

Figure 1. Big Class Writers' Room, a collaboration between Small Center and 826 New Orleans.

\section{INTRODUCTION}

Deeply engaged and collaborative design is the hallmark of any good architectural design practice or institution. Private practices are increasingly interested in transforming their pro-bono and public work to meet the rigorous standards necessary to both strive for design excellence and effect meaningful change. This paper offers guiding principles that our practice uses as we work toward lasting social change through collaborative design.

The research, education, and design practice of the Albert and Tina Small Center for Collaborative Design focuses on working closely with New Orleans non-profit organizations and neighborhood groups to achieve their programmatic goals through high quality design. This work supports bottom-up social change at the community scale by connecting partners and resources, expanding access to design services, and considering the public-facing aspects of all projects. Our partner organizations (typically non-profits in the New Orleans bring their project ideas to us, and we bring our design expertise to bear in collaboration, supporting New Orleans residents in imagining and pursuing projects that strengthen neighborhoods and contribute to a city shaped by its residents. Our applied research process and collaborative working model help to correct a tendency of designers to solely address spatial concerns and can highlight submerged social issues that must equally be addressed. 
Each year, an assembled jury of past project partners, community leaders, philanthropy, and designers select projects by prioritizing partner ideas that have the potential to address inequity. We believe in participatory project scoping and framing prior to project selection to avoid the inclination to respond to non-design problems with design solutions. We work to assemble interdisciplinary teams who tackle challenges that reach beyond our design expertise, and sometimes our role is simply to convene conversations between people who have similar ideas or face similar challenges to find a shared path forward.

When selecting partners, the Small Center focuses on organizations that are deeply rooted in the communities they serve and address a wide range of issues ranging from affordable housing and homelessness to water management and food security. We use the design process as a means to convene new allies and supporters for our partner organizations, expanding their organizational capacity, while strategically including their current stakeholders, staff, and end users. Once a partnership begins, the team holds multiple meetings with the community partners to learn more about the proposed project. Within these initial meetings, we collectively define success for the project, outline the parameters of our work, and define goals within three categories: an appropriate design product, a stronger coalition for advocacy, and the education of young designers. All projects are developed in a collaborative process that engages the organization's constituents and stakeholders to better shape the final design and strengthen the organization's network.

This engagement and design process is one that we have been expanding and refining since the Small Center's founding in 2005. In that time we have collaborated on several hundred projects ranging from small scale design build projects to large scale urban planning. These collaborations have challenged and informed the way we work, and have shaped our guiding engagement principles: Build Consensus, Build Power, Build Accountability, Build Understanding, and Build a Bigger Table. This article uses project case studies to articulate these engagement principles, focusing on a key project known as Parisite Skatepark.

\section{CASE STUDY:}

PARISITE SKATEPARK, NEW ORLEANS, LOUISIANA

Parisite Skatepark is the only official skatepark in the City of New Orleans. Sited at the corner of Paris Avenue and Pleasure Street, the park is located in a historically underserved neighborhood and was initially created by a group of ambitious young skaters who took advantage of the vacant, under-utilized space. Word spread fast and the guerrilla skate park known as The Peach Orchard was established. The local skaters taught themselves how to design, build and maintain the skatepark until the city demolished the site citing public safety concerns. In 2010, the skaters started the Do-It-Yourself skatepark at the intersection of Interstate 610 and Paris Avenue (hence

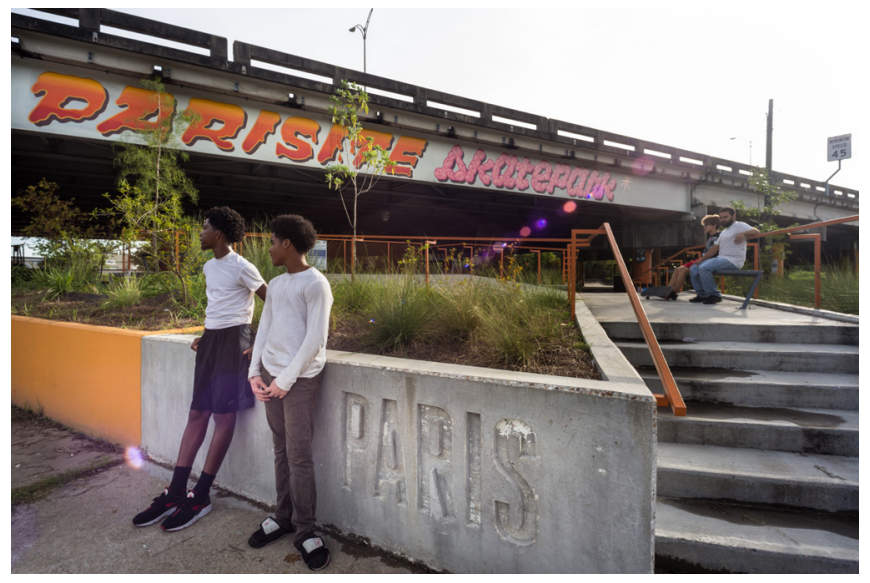

Figure 2. Parisite Skatepark entrance, New Orleans, Louisiana.

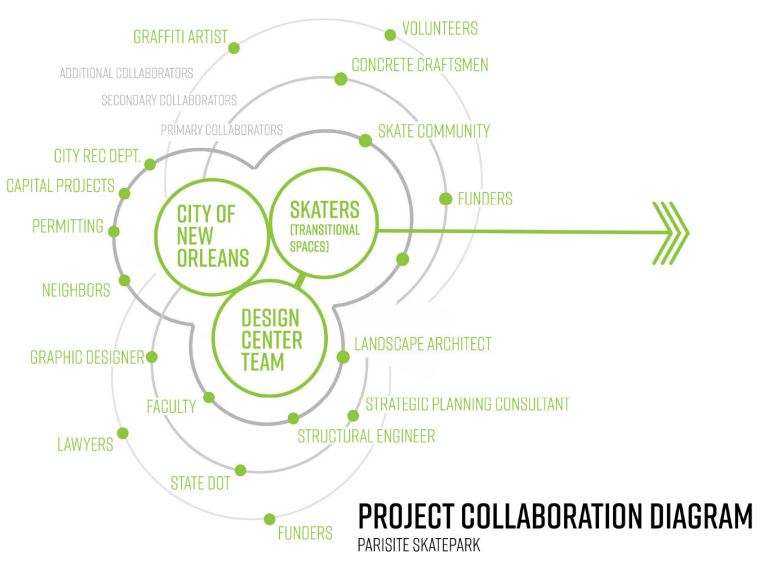

Figure 3. Diagram of skatepark project primary partners and the network of collaborators.

the name 'Paris Site'). With growing popularity, this informal public space once again drew the attention of city officials who questioned the legal implications of operating such a recreational space. The city made clear its plans to demolish the fledgling skatepark, which was under a federal interstate. The skaters approached the Small Center for technical and design assistance to protect the park and continue its build out.

Small Center's work began by building organizational capacity. The Small Center supported the skaters as they formed a nonprofit organization, Transitional Spaces. The Center increased the organization's understanding of regulatory and permitting processes and their capacity to engage and negotiate with public entities, lending legitimacy to the project. Transitional Spaces became strong advocates for the park, and not only convinced the city to declare the site an official skatepark, but succeeded in getting a set of ramps placed on the site through a donation by Red Bull/Sphon. Through time, strategic partnerships, and a series of state 


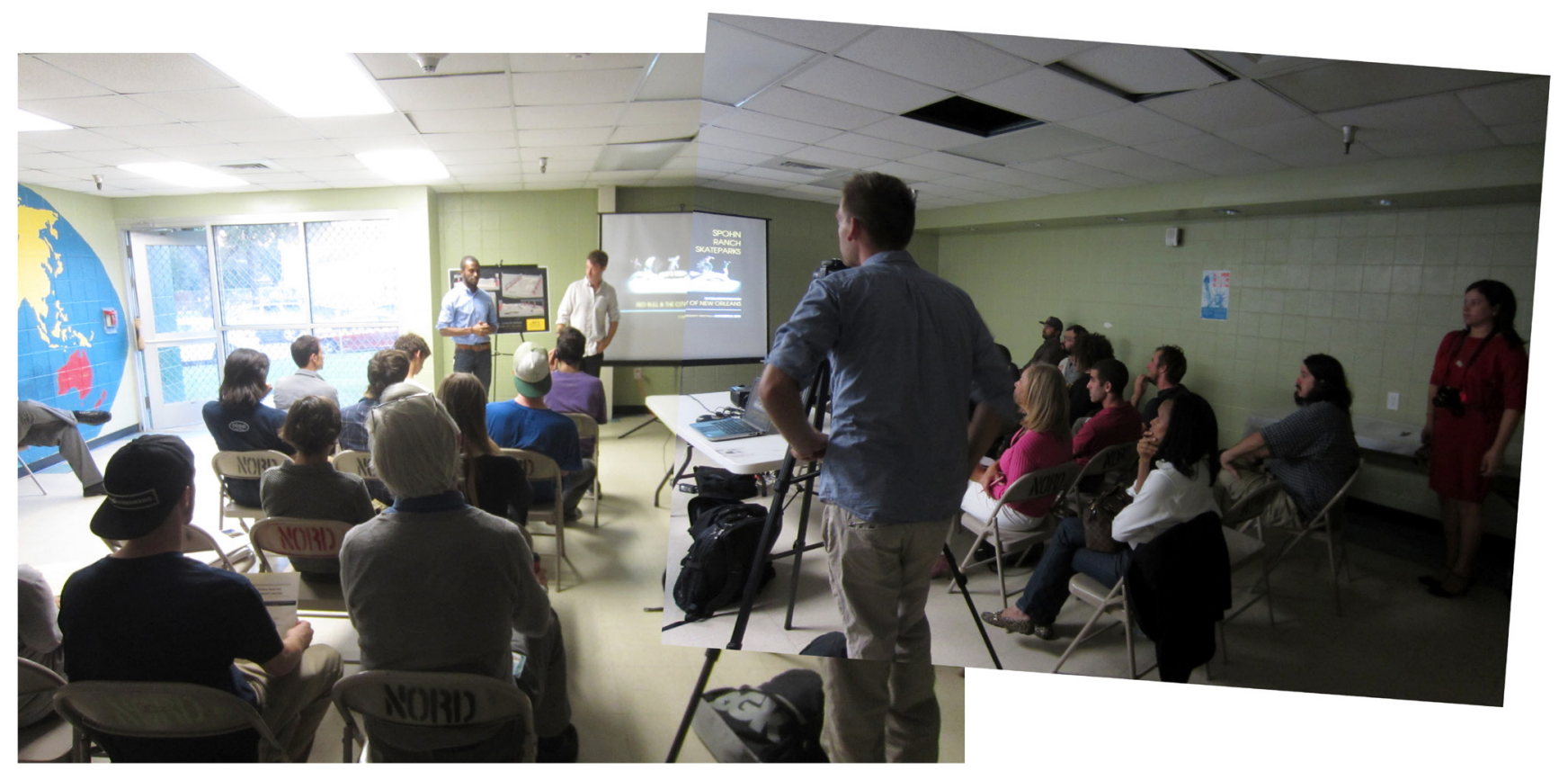

Figure 4. Neighborhood presentation and feedback session led by Transitional Spaces members.

and local approvals, the grassroots public park became New Orleans' first official skatepark.

In addition to capacity building, the Small Center worked with Transitional Spaces to develop a vision for the park. The masterplan included specific designs for an entrance, signage, planting, benches and handrails to make the skatepark a welcoming community park space. Planted areas address the need for stormwater catchment and filtration from the skatepark and the highway overpass. Small Center constructed the entryway and various other park amenities on site and over the last few years Transitional Spaces has continued the phased buildout of more ramps and skateable features. In addition to creating a masterplan for growth, as well as providing capacity building for the non-profit, the Small Center helped the organization connect to legal, engineering, and other professional support necessary to grow Parisite into a fully operational public space.

\section{BUILD CONSENSUS}

Going beyond the typical "neighborhood meeting" and prioritizing consensus building allows individual projects to serve as a means to address larger contextual problems. Building consensus requires the development of an inclusive design process that seeks multiple sources of input through diverse means as early in the process as possible and remains flexible enough to adapt to unknown outcomes. This inclusive design process offers an opportunity to ensure projects have buy-in from a range of stakeholders including clients (in our case non-profit organizations), end-users, neighbors and city agencies. Deep engagement before the design conversation ever begins, and broad involvement during the design process itself bolsters the project's impact and long-term sustainability by ensuring it is addressing stated needs, and that all parties understand what is necessary for the project to succeed in the short and long term. This requires all organizations involved in the project to pull on their extensive networks of clients, collaborators, consultants, and advocates to engage in dialogue, shape the project and support its execution.

\section{In Action}

For Parasite Skatepark, successive design charrettes and community gatherings that adapted location, content, and engagement methods to the audience were at the core of consensus building efforts. We met with the skate community (skaters, bikers, the local roller-girl team) to discuss ideas both on-site and in a local artist's studio space. Brainstorming activities ranged from more traditional paper surveys and sketching sessions to forming play-dough master plans on large wooden site models. These sessions were often paired with existing on-site activities. Go Skate Day offered an opportunity for skaters and their families to test full-scale moveable prototypes while enjoying food and music.

More traditional "neighborhood meetings" were held at a city recreation center adjacent to the skatepark. At these meetings, presentations were led by skaters, extensive question and answer time was provided and input sheets offered an additional opportunity for neighbors to express their ideas and 


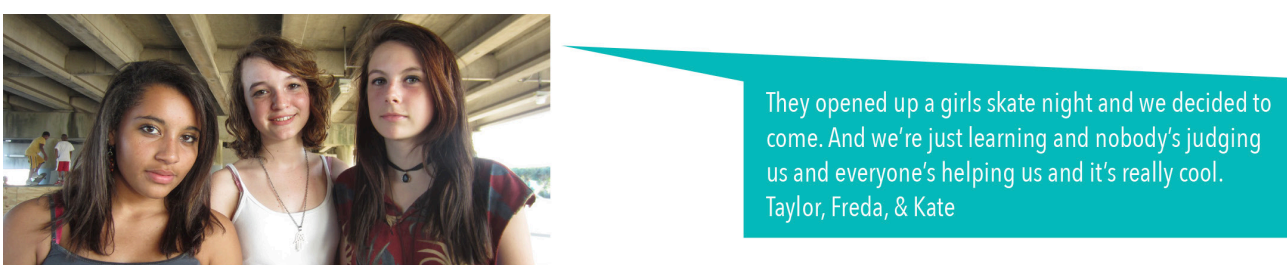

This is why we came. This is why we drove two and a half hours to

this city, to be here at Parisite. If you want to know what is going to

bring people to New Orleans, this is what is going to bring them here.

Lee Trahan \& Friends
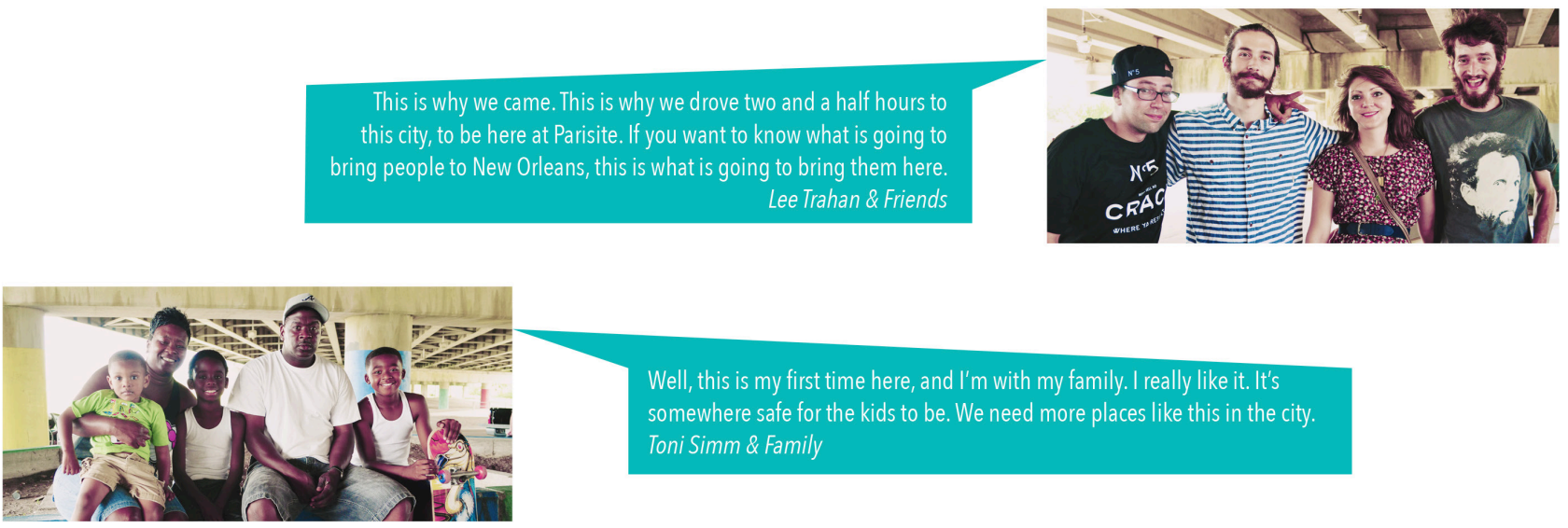

Well, this is my first time here, and I'm with my family. I really like it. It's

somewhere safe for the kids to be. We need more places like this in the city.

Toni Simm \& Family

This place is great, built by skaters for skaters. So, it is everything we

want because we built it ourselves. I'd love to see a bowl here

sometime soon. We should get working on that

Tommy "Bama" Stevens

concerns. Fliers on porches and conversations with neighbors were used to spread the word about meeting dates, times and agendas. With each subsequent meeting, a recap of what had been discussed and leading ideas to date were shared so the dialogue could continue to build. This process allowed trust to be established and maintained between all parties. In addition, the city's Capital Projects team often attended events and meetings, gave input on proposals, shared regulatory challenges, and offered potential solutions. They were provided regular project updates, ensuring they were an integral part of the team and committed to the execution of the project. The city's active engagement allowed them to see the capacity of the partner, the importance of user involvement in decision-making regarding recreation spaces, and offered an opportunity to highlight the importance of high quality design and the important role of architects in public projects.

\section{BUILD POWER}

Simple recognition of multiple forms of expertise and inclusion of input from a range of voices allows a design process to build power. This requires a model of collaboration in which partners work together to frame the initial project before designs are ever created or policies implemented. It also requires open conversations about the power dynamics at play in any given project or situation. Often in pro-bono work there is a dynamic wherein the designer is "giving" design services to a client who feels they have to be thankful for whatever they get. We start our project partnerships by talking through these dynamics, proposing a different vision of the design process, and clarifying each party's active role in shaping the project and providing feedback. This small step in the early part of the design process allows us to understand more clearly how we can build power and advocate for our project partners, and builds trust that enhances the project moving forward. It also signals to the partner our willingness to transfer power, a priority and necessity in our work. Often a focus on sharing information widely and decoding unnecessarily complex regulatory information are key components to building power.

\section{In Action}

For the city to grant legitimacy to the skatepark and allow further work to be done on-site, they needed an organization to coordinate and negotiate the ongoing development of the park's vision. In forming Transitional Spaces, the skate community had a legal entity but little knowledge of how to run or maintain a non-profit. Our team recognized that this problem did not require a design solution. Instead, we 
brought in an ally from our network who was well-versed in running a nonprofit. After a multi-day bootcamp on nonprofit organizational management and connecting to our local university's legal services, Transitional Spaces was able to function more effectively as a partner to the city. This included the capacity to sign a memorandum of understanding committing to maintenance and upkeep of the park, which was a key condition of city approval. Additionally, we were able to leverage the power of our umbrella entity, Tulane University, and its involvement in the project to halt the city's demolition plans and convince them to take seriously both Transitional Spaces as an organization and their vision and commitment to the space.

Beyond the more dry and technical ways we worked to support and build power within our partner organization, careful thought and effort was put into who would speak at community meetings and events as the project spokespersons. We recognized there was a need to challenge stereotypical ideas about skaters and skate culture. Skaters presented the design work, precedents, and master planning, and spoke as experts in the park's creation. This served as an additional way to further legitimize and solidify the partner, and by extension the project.

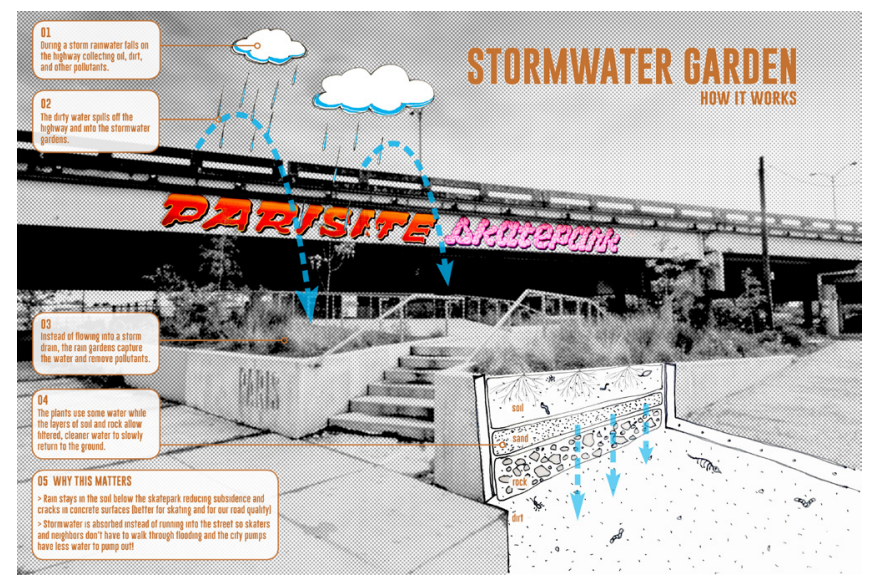

Figure 6. Educational signage installed on site.

\section{BUILD ACCOUNTABILITY}

It is a focus on accountability before, during and after a design process that promotes trust and strengthens designers' ability to play an enhanced role in promoting equitable and inclusive development. Prior to a project, It is important to understand whether the collaborative team is properly framing the perceived problems or challenges that define the project. Early conversations with partners allow clarification of project goals and offer an opportunity to articulate roles and responsibilities. Often in the process of design, focus can be captured by opportunities, but also diverted by challenges that grow beyond their importance or relevance to the actual goals of the project, and thus impeding progress towards the original goals. Again, open and frequent dialogue between the designers, partners, and stakeholders can help by revisiting and reaffirming project goals to ensure that everyone is working together to address the initially identified issues. Likewise, communication and collaboration with stakeholders and consultants can act as a check on incorrect assumptions or unseen opportunities. Developing metrics to assess the impact of design projects, both built and unbuilt, offers us another opportunity to ensure we are responding to the needs of our partner organizations after projects are completed.

\section{In Action}

Early in the design process our students focused their research and design efforts on skateparks and skateable elements. After several rounds of interviewing stakeholders it became evident that our design focus should also include stormwater management infrastructure and additional park amenities. The site, under a federal interstate, was in an ideal location for a skatepark in our hot and wet climate since it provided constant shade, and theoretically protection from the rain. In reality, the rain was a constant nuisance as it sheeted off the interstate and flooded through the concrete slab, making it difficult to skate. Managing the water from the interstate became a key driver of design and resulted in stormwater gardens being integrated into the park entrance. In addition, we interviewed many family members who were at the park to watch and support their children yet had no good place to sit while doing so. The master plan proposals grew to include more traditional elements such as benches, bike racks, native landscaping, and shade trees in order to augment the skateable spaces. At the same time, throughout the process we worked to understand priorities and capacities of the partners in order to narrow the scope of the project to what our design-build team and the project's stakeholders could achieve. Understanding the needs of stakeholders and nuances of the park, interviews from the design process

\section{BUILD UNDERSTANDING}

We don't know everything. Incorporating a range of perspectives and expertise is an asset to the development of the project. Each of our projects includes interviews and research as an ongoing aspect of the design process. It helps to look at design problems from diverse perspectives, particularly nondesign perspectives. Building understanding can also include helping our partners better understand their constituencies, whether it is those using the facility, maintaining it, or potential funders and allies. This process can uncover contradictions within a project's goals but can just as often produce new ways to frame or solve an issue. 

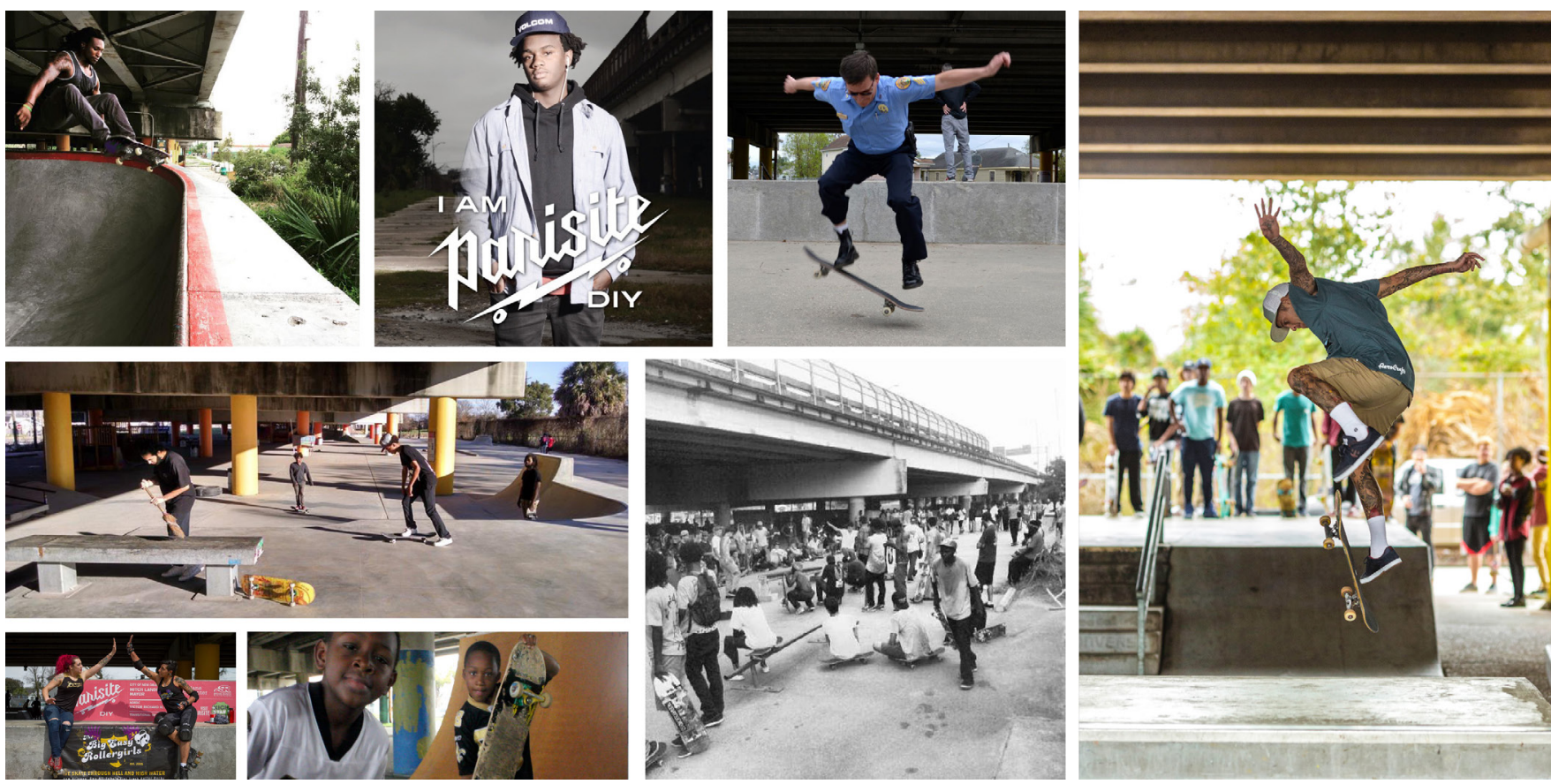

Figure 7. Parisite Skatepark in-use.

\section{In Action:}

In the process of master planning Parisite we discovered that the city had been gifted $\$ 250,000$ of skate ramps from Red Bull, but were paying to store these ramps indefinitely with no place for installation. The skate community initially balked at the idea given the style of skating those ramps were built for but eventually decided that including the Red Bull ramps in the early phases of Parisite's master plan was a way to solve problems, define space, and start to create a site strategy that could be built out over time. Furthermore, the phased buildout strategy that developed allowed the park to respond to changes in skater's input and needs and continue the D.I.Y. vibe that so inspired the early park community but in a city-sanctioned way. The decision to include those prefabricated pieces also had ramifications on the master plan that necessitated further conversations with neighbors about parking and construction timeline yet also built a considerable amount of attention and excitement about the quick progress taking place at the park.

\section{BUILD A BIGGER TABLE}

Throughout our work, Small Center's approach is to make every effort to find new perspectives and voices in our community, to keep listening, learning, and asking questions. During projects, we include as many voices as possible in the spaces where decisions are being made. We also strive to ensure that after the design (or design-build) process is done, the ideas and teachable moments in the projects live on. In a very basic way, this means we capture the process and result of each project in a booklet which is printed, distributed, and available for download. Similarly, with our exhibitions we capture and share the information online through free pdf's or interactive websites. In our built projects, information sharing and outward facing education can take various forms from educational signage to on-site workshops and demonstrations.

\section{In Action}

For the design and build of the skatepark, collaborators included the startup skater organization, Transitional Spaces; Small Center design team; New Orleans Recreation Development Commission; the local skater community; a structural engineer; a landscape architect; neighbors; the Louisiana Department of Transportation; a strategic planning consultant; concrete craftsmen; a graffiti artist; funders, including the Surdna Foundation and Johnson Controls, Inc.; lawyers; and a small army of volunteers. The project design and build process was designed to create a roadmap for Transitional Spaces and a network of advocates and consultants to help with the funding, permitting, and construction of future phases. The site continues to be built out in a process entirely run by Transitional Spaces and approved by city and state agencies. We consider the continued development of the park without our active involvement to be one of the most successful aspects of the early design-build work.

In addition, the design of a stormwater management strategy on site speaks to a larger issue for New Orleans in general as it struggles to live with water. After construction, signage was 
installed at the park that explains these features of the project and shares design intention. These signs provide an ongoing opportunity to educate and engage a diverse audience how the space functions and the importance of green infrastructure as a means to address stormwater management.

\section{CONCLUSION}

Community engagement is a key element of public interest design, which takes as its goal design as a tool for creating a better world for the people who happen to inhabit it. So we're interested in buildings, the built environment, and in space broadly, but we're really interested in the social use of space. Our hope is that this framework for engagement can thoughtfully interrogate social and physical context, challenge underlying assumptions, and design with, rather than for people. Just as spatial concerns cannot stand alone, the building blocks of this framework - consensus, understanding, accountability, power, a bigger table - are inherently interconnected. Consensus building requires recognition of power dynamics and transfer of power between designer and partner; building a bigger table allows and necessitates deeper understanding and a commitment to accountability supports both the sustainability of projects and growth of relationships. Commitment to all these principles in unison ensures that our projects are conceived and executed in collaboration with the people who will be most impacted by the work.

While Small Center is based in a university setting, we contend that our work in defining truly collaborative design processes can be translated to professional practice as an ethic and even in executing individual projects. We work to prepare the next generation of architects to design boldly while working collaboratively, and to bring a critical lens on equity to every design discussion. Private practice is dedicating more resources to pro-bono work, but in both this and the for-profit sphere, should focus on the time afforded to collaborative processes that not only shape design but the process of design itself. This is one way for the profession to avoid standing on the sidelines while battle for a more equitable society is fought, as Whitney Young, Jr. reminded us, and is necessary in the pursuit of design and projects that will effect meaningful change.

Beyond expanding who designers serve, increasing understanding of the role of design and shifting perceptions of who high-quality design is for, does a commitment to engaged practice shift the needle on the complex challenges facing our cities? If yes, how? If no, does our practice need to evolve? These are the questions we ask ourselves as we work in New Orleans and beyond. Through coalition building across organizational and socioeconomic divides, creation and distribution of accessible education and outreach materials, and collaborative design processes, our experience represented by the case studies above indicate yes. We recognize these case studies are only a part of the picture. Our dedication to accountability and interrogating our own practice requires us to commit to deepening our understanding of impact through ongoing research and concrete evaluation. These results will inform our collaborative practice moving forward. 